\title{
New Control Strategy To Improve Power Quality Using A Hybrid Power Filter
}

\author{
S. P. Litrán, P. Salmerón, R. S. Herrera, and J. R. Vázquez \\ Department of Electrical Engineering \\ Escuela Politécnica Superior, University of Huelva \\ Ctra. de Palos de la Frontera s/n 21819, Palos de la Frontera. Huelva (Spain) \\ Phone: +0034 959 217585, Fax number: +0034 959217304 \\ e-mail: salvador@uhu.es; patricio@uhu.es; reyes.sanchez@die.uhu.es; vazquez@uhu.es
}

\begin{abstract}
A new control algorithm for a hybrid power filter constituted by a series active filter and a passive filter connected in parallel with the load is proposed. The new control strategy is based on the dual formulation of the vectorial theory of electric power, so that the signal injected by the active filter is able to compensate the reactive power and the harmonics of the load current. To verify the developed theoretical analysis, the control strategy was verified by means of an experimental prototype. The results to verify the effectiveness of the proposed control algorithm are presented.
\end{abstract}

\section{Key words}

Harmonics, series active power filter, hybrid power filters, power quality, compensation, pq theory.

\section{Introduction}

The presence of harmonics in the power electrical systems is the main cause of the electrical wave pollution that so many problems carry. The indiscriminate increase of non-linear loads has given rise to investigation into new compensation equipment based on power electronics. The main design target for this equipment is the elimination of the harmonic present in the system and a reduction in the power reactive. Depending on the application type, series or parallel configurations or combinations of active and passive filters have been proposed $[1,2]$.

When the objective is to compensate current-source nonlinear loads, named harmonic current source (HCS), a shunt configuration as compensation equipment is used. To eliminate harmonics in this kind of load, a shunt passive filter have traditionally been used, mainly due to their low cost and minimal maintenance requirements. As a result, this has been the adopted solution for systems with considerable power. However, shunt passive filters are not free from problems [3] of which the most significant are:
-The compensation characteristics depend strongly on the system impedance as the filter impedance has to be smaller than the source impedance in order to eliminate source current harmonics.

-Overloads can happen in the passive filter since they can finish being harmonics drain of other connected nonlinear loads near the point of common coupling, PCC.

- They are not appropriate for loads of variable operation, since, on one hand, they are designed for a specific reactive power, and on the other, the variation in the values of the load can detune the filter.

-Series and/or parallel resonances with the rest of the system can appear.

On the other hand, it is possible to improve the behavior of passive filters in parallel connection by including a series active filter in the system. This improves the compensation characteristics of the passive filter [4]. This topology is shown in Fig. 1, where $\mathrm{v}_{\mathrm{c}}$ is the voltage that the active power filter should generate to achieve the objective of proposed control algorithm.

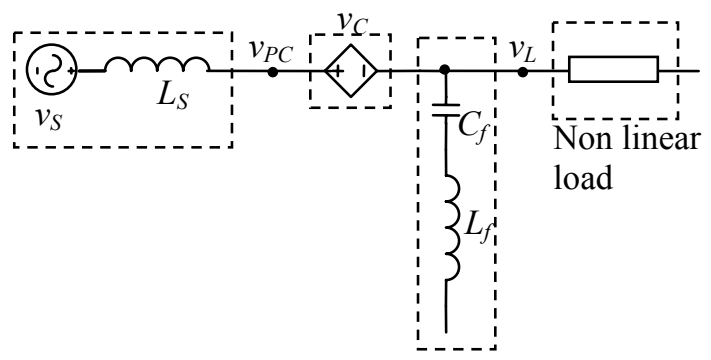

Fig. 1. Series active filter with shunt passive filter

Different techniques have been applied to obtain the control signal to the active filter series. One of them is to generate a proportional voltage to the harmonic of the 
source current [5]. However, the choice of the appropriate value for the proportional constant is an unsolved question since it is related to the value of the passive filter and the source impedance. Another technique of propose control is to generate a voltage waveform like to the voltage harmonic in the side load but in opposition. This strategy only prevents the shunt passive filter depending on the source impedance, [6].

Later, a control strategy that combining both the above have been used [6], but they continue to suffer the difficulty of an indefinite value for the constant $\mathrm{k}$ in most of the applications.

A recent strategy proposes that the active filter generates a voltage which compensates the reactive power of the passive filter and load set and allows elimination of the current harmonics [7]. There, the control target is to achieve constant power in the source side.

In this paper a new control strategy based on the dual formulation of the vectorial theory of electric power [8$10]$ is proposed. It allows the voltage that the active filter has to generate to be determined so as to attain the compensation objective of achieving is to obtain a sinusoidal voltage in PCC. With this strategy it is possible to improve the compensation characteristics of the passive power filter without depending on the system impedance, since the set load-filter would have a behavior very similar to the one of a resistive element. It also avoids the danger that the passive filter will behave as a harmonic drain of near loads, and likewise the risk of possible series and/or parallel resonances with the rest of the system. In addition, the compensation is also possible for variable loads, not affecting some possible detuning of the passive filter.

The system has been verified by means of an experimental prototype, applied to a nonlinear threephase load. The experimental results are presented.

\section{Control strategy}

In a three phase system, the coordinates transformation from the phase reference system $a-b-c$, to $\alpha-\beta-0$ coordinates of the voltages and currents can be obtained by

$$
\begin{aligned}
& {\left[\begin{array}{l}
v_{0} \\
v_{\alpha} \\
v_{\beta}
\end{array}\right]=\sqrt{\frac{2}{3}}\left[\begin{array}{ccc}
1 / \sqrt{2} & 1 / \sqrt{2} & 1 / \sqrt{2} \\
1 & -1 / 2 & -1 / 2 \\
0 & \sqrt{3} / 2 & -\sqrt{3} / 2
\end{array}\right]\left[\begin{array}{l}
v_{a} \\
v_{b} \\
v_{c}
\end{array}\right]} \\
& {\left[\begin{array}{c}
i_{0} \\
i_{\alpha} \\
i_{\beta}
\end{array}\right]=\sqrt{\frac{2}{3}}\left[\begin{array}{ccc}
1 / \sqrt{2} & 1 / \sqrt{2} & 1 / \sqrt{2} \\
1 & -1 / 2 & -1 / 2 \\
0 & \sqrt{3} / 2 & -\sqrt{3} / 2
\end{array}\right]\left[\begin{array}{l}
i_{a} \\
i_{b} \\
i_{c}
\end{array}\right]}
\end{aligned}
$$

The real instantaneous power in the frame $\alpha-\beta-0$ is calculated as follows

$$
p_{3 \phi}(t)=v_{\alpha} i_{\alpha}+v_{\beta} i_{\beta}+v_{0} i_{0}
$$

This power can be written by means of

$$
p_{3 \phi}(t)=p+p_{0}
$$

Where $p$ is the real instantaneous power without the zero sequence real instantaneous power and given by

$$
p=v_{\alpha} i_{\alpha}+v_{\beta} i_{\beta}
$$

This power can be written in vectorial form by means of the dot product

$$
p=i_{\alpha \beta}^{T} v_{\alpha \beta}
$$

Where $i_{\alpha \beta}^{T}$ is the transpose of the current vector in coordinates $\alpha-\beta$

$$
\boldsymbol{i}_{\boldsymbol{\alpha} \boldsymbol{\beta}}=\left[\begin{array}{ll}
i_{\alpha} & i_{\beta}
\end{array}\right]^{T}
$$

And $v_{\alpha \beta}$ is voltage vector in the same coordinates

$$
\boldsymbol{v}_{\boldsymbol{\alpha} \boldsymbol{\beta}}=\left[\begin{array}{ll}
v_{\alpha} & v_{\beta}
\end{array}\right]^{T}
$$

In the equation of the real instantaneous power (4), $p_{0}$ is the zero sequence real instantaneous power, determined as follows

$$
p_{0}=v_{0} i_{0}
$$

In a three wire system the zero sequence real instantaneous power is null.

The imaginary instantaneous power is defined by the equation

$$
q \hat{=} v_{\alpha} i_{\beta}-v_{\beta} i_{\alpha}
$$

This can be expressed by means of the dot product

$$
q=i_{\alpha \beta \perp}^{T} v_{\alpha \beta}
$$

Where $i_{\alpha \beta \perp}^{T}$ is the transpose of the current vector perpendicular to $i_{\alpha \beta}$ and defined by,

$$
\boldsymbol{i}_{\boldsymbol{\alpha} \boldsymbol{\beta} \perp}=\left[\begin{array}{ll}
i_{\beta} & -i_{\alpha}
\end{array}\right]^{T}
$$

According to these terms, both power variables previously defined can be expressed by

$$
\left[\begin{array}{c}
p \\
q
\end{array}\right]=\left[\begin{array}{c}
\boldsymbol{i}_{\alpha \boldsymbol{\beta}}^{T} \\
\boldsymbol{i}_{\alpha \boldsymbol{\beta} \perp}^{T}
\end{array}\right] \boldsymbol{v}_{\alpha \boldsymbol{\beta}}
$$


By means of the current vectors and the instantaneous real and imaginary power, the voltage vector can be calculated as,

$$
\boldsymbol{v}_{\alpha \boldsymbol{\beta}}=\frac{p}{i_{\alpha \beta}^{2}} \boldsymbol{i}_{\boldsymbol{\alpha} \boldsymbol{\beta}}+\frac{q}{i_{\alpha \beta}^{2}} \boldsymbol{i}_{\boldsymbol{\alpha} \boldsymbol{\beta} \perp}
$$

In order to achieve the desired compensation target, the current and the voltage source must be proportional

$$
\boldsymbol{v}_{S_{\alpha \beta}}=R_{e} \boldsymbol{i}_{S 1 \alpha \beta}
$$

Where $\boldsymbol{i}_{S I}$ is fundamental current component in the supply side and $R_{e}$ is the equivalent resistance which is defined by the following expression,

$$
R_{e}=\frac{P}{I_{1}^{2}}
$$

In this equation $I_{l}^{2}$ is the square rms value of the fundamental harmonics of the current vector and $P$ is the active power consumed by the load.

Therefore the voltage at the point of common coupling after compensation will be as follows,

$$
\boldsymbol{v}_{P C \boldsymbol{\alpha} \boldsymbol{\beta}}=\frac{P}{I_{1}^{2}} i_{1 \boldsymbol{\alpha} \boldsymbol{\beta}}
$$

The load voltage is given by

$$
\boldsymbol{v}_{L \boldsymbol{\alpha} \boldsymbol{\beta}}=\frac{p}{i_{\alpha \beta}^{2}} \boldsymbol{i}_{\boldsymbol{\alpha} \boldsymbol{\beta}}+\frac{q}{i_{\alpha \beta}^{2}} \boldsymbol{i}_{\boldsymbol{\alpha \beta} \perp}
$$

Where $p$ is the real instantaneous power and $q$ is the imaginary instantaneous power of the load.

The reference voltage of compensation injected by the active power filter is calculated as

$$
v_{\alpha \beta}^{*}=v_{P C \alpha \beta}-v_{L \alpha \beta}
$$

Thus, the compensation voltage considering equations (17) and (18) is given by

$$
\boldsymbol{v}_{\alpha \boldsymbol{\beta}}^{*}=\left(\frac{P}{I_{1}^{2}}-\frac{p}{i_{\alpha \beta}^{2}}\right) \boldsymbol{i}_{\alpha \boldsymbol{\beta}}-\frac{q}{i_{\alpha \beta}^{2}} \boldsymbol{i}_{\alpha \boldsymbol{\beta} \perp}
$$

When the active power filter supplies this compensation voltage, the set load and compensation equipment will behave very similar as a resistance of value $R_{e}$.

Fig. 2 shows the control scheme to calculate the compensation voltage for the active filter. The voltage vector in the side of the load and the source current vector are the input signals. By means of a calculation block the components $\alpha-\beta$ of the vectors $\boldsymbol{v}_{\alpha \beta}$ e $\boldsymbol{i}_{\alpha \beta}$ can be determined. The product of these vectors allows the real instantaneous power to be calculated, obtaining its mean value with a low pass filter (LPF). This power is consumed by the set passive filter and load. The mean power is divided by the square of $\mathrm{rms}$ value of fundamental current component.

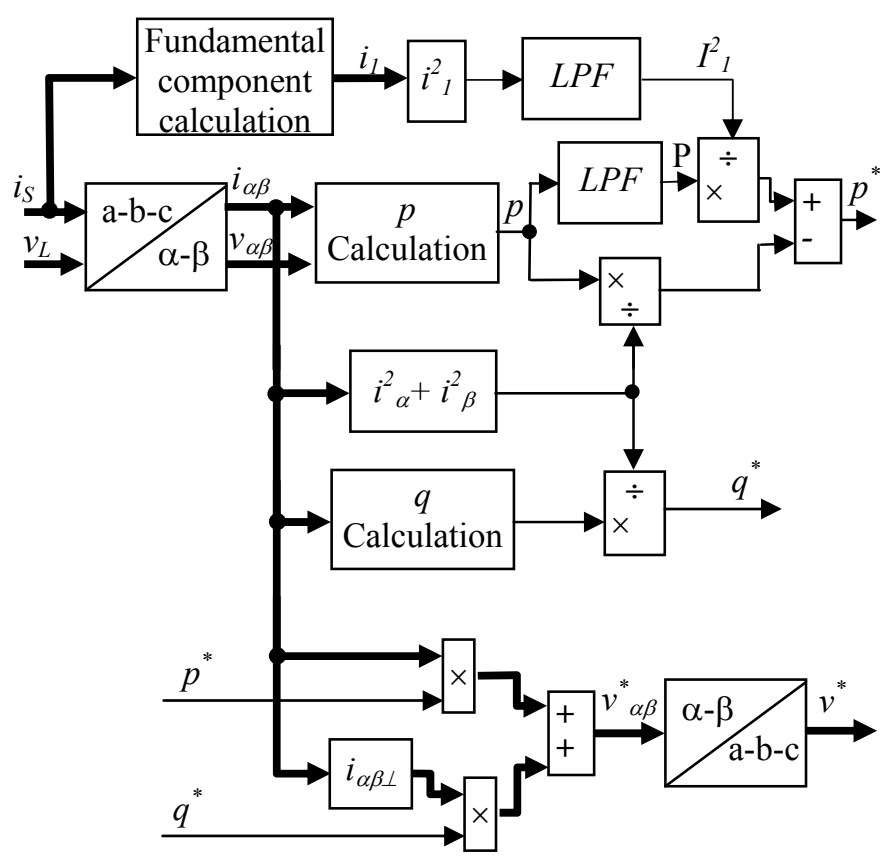

Fig 2. Control scheme

The fundamental component is obtained by means of a block with the scheme shown in Fig. 3. The source current vector is multiplied by $\sin \omega t$ and $\cos \omega, t$ where $\omega$ is the fundamental frequency in $\mathrm{rad} / \mathrm{s}$. The mean values of the results are obtained by two low pass filters and aided by the function $\sin \omega t$ and $\cos \omega t$. This allows us to obtain the fundamental component of the current vector; on the other hand, the real instantaneous power is divided by $i_{\alpha \beta}^{2}$. This result is multiplied by the current vector $\boldsymbol{i}_{\alpha \beta}$, which allows us to determine the first term of the compensation voltage of the equation (20).

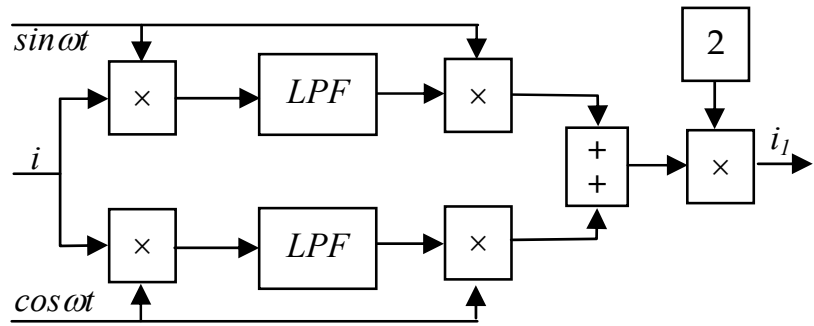

Fig. 3. Calculation fundamental component

On the other hand, the imaginary instantaneous power is obtained and divided by $i_{\alpha \beta}^{2}$ and finally multiplied by the current vector $\boldsymbol{i}_{\alpha \beta \perp}$. It allows the second term in the 


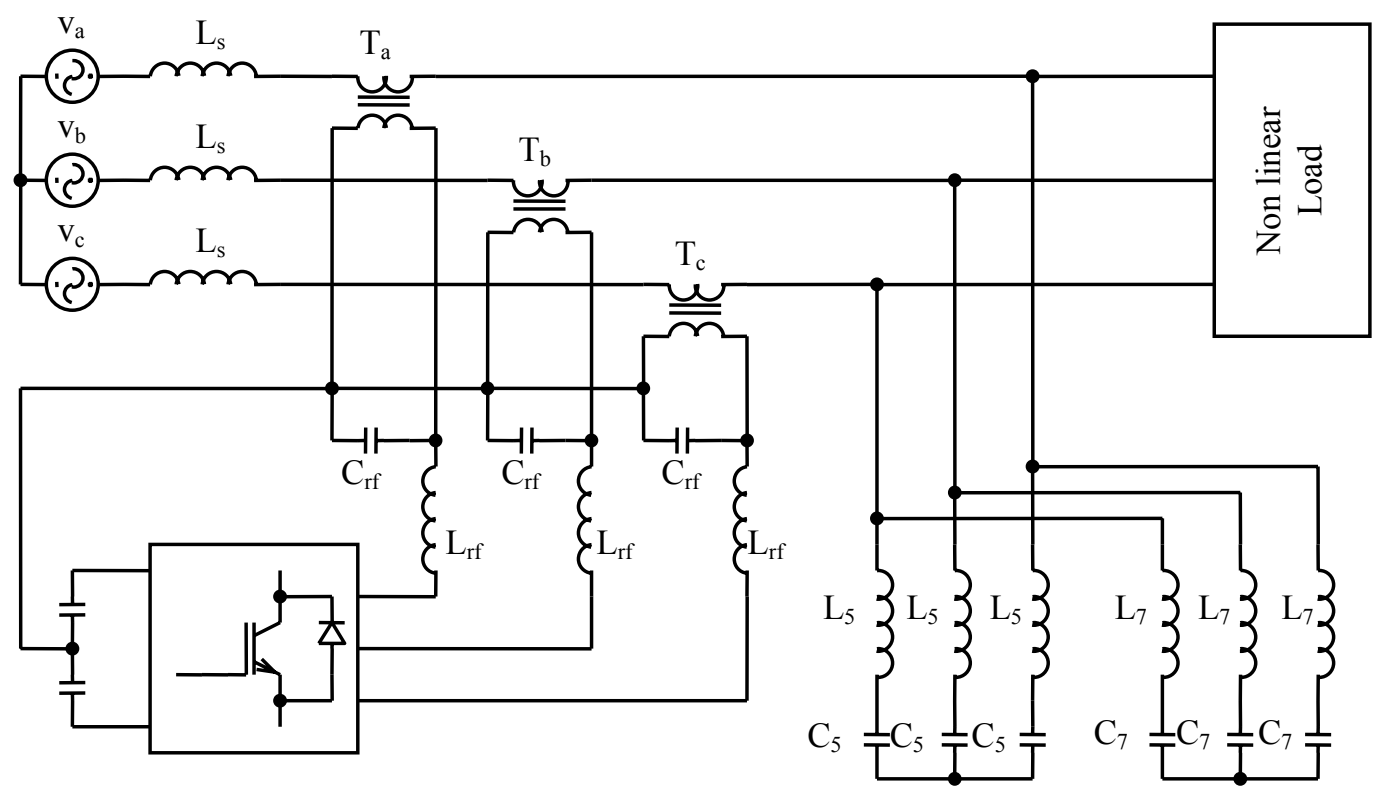

Fig. 4. Passive filter combined with series active power filter topology.

equation for the compensation voltage (20) to be obtained.

The control strategy was verified with a model simulated in the platform Matlab-Simulink using the toolbox library of SimPowerSystem. Later an experimental prototype was manufactured.

\section{Experimental prototype}

Fig. 4 shows the scheme of the power circuit. It is a three-phase three-wires system supplied by a sinusoidal balanced three-phase source of $100 \mathrm{~V}$ rms with source inductance of $5 \mathrm{mH}$.

The converter consists of an IGBT bridge, type SKM50GB123 from Semikron. In the dc side two capacitors with $100 \mathrm{~V}$ are connected. In the ac side a LC filter has been included to eliminate the high frequency components. This set is connected to the power system by means of three single phase transformers of turn ratio $1: 1$.

The passive power filter is making by two LC branches tuning to the $5^{\text {th }}$ and $7^{\text {th }}$ harmonics. The values of each passive element are included in the table I.

TABLE I. Passive elements values

\begin{tabular}{|l|c|c|}
\hline Source & \multicolumn{2}{|c|}{$\mathrm{Ls}=3.4 \mathrm{mH}$} \\
\hline \multirow{2}{*}{ Pasive filter } & $\mathrm{L}_{5}=13.5 \mathrm{mH}$ & $\mathrm{C}_{5}=30 \mu \mathrm{F}$ \\
\cline { 2 - 3 } & $\mathrm{L}_{7}=6.75 \mathrm{mH}$ & $\mathrm{C}_{7}=30 \mu \mathrm{F}$ \\
\hline Ripple filter & $\mathrm{L}_{\mathrm{r}}=13 \mathrm{mH}$ & $\mathrm{C}_{\mathrm{r}}=50 \mu \mathrm{F}$ \\
\hline
\end{tabular}

The non linear load consists of a non controller three phase rectifier with an inductance of $55 \mathrm{mH}$ and a resistance of $50 \Omega$ connected in the dc side.
The control was implemented in control and data acquisition cards of general application, compatible with Matlab-Simulink developed by dSPACE.

Real-Time Interface (RTI) of dSPACE together Real Time Workshop (RTW) from Mathworks automatically generates real time code on dSPACE. It allows to program the processor board and to select I/O boards. It is based on the DS 1005 PPC placed in a dSPACE expansion box. The input board was the DS 2004 A/D and the output board the DS 51001 DWO from dSPACE.

The developed experimental prototype is shown in Fig. 5.

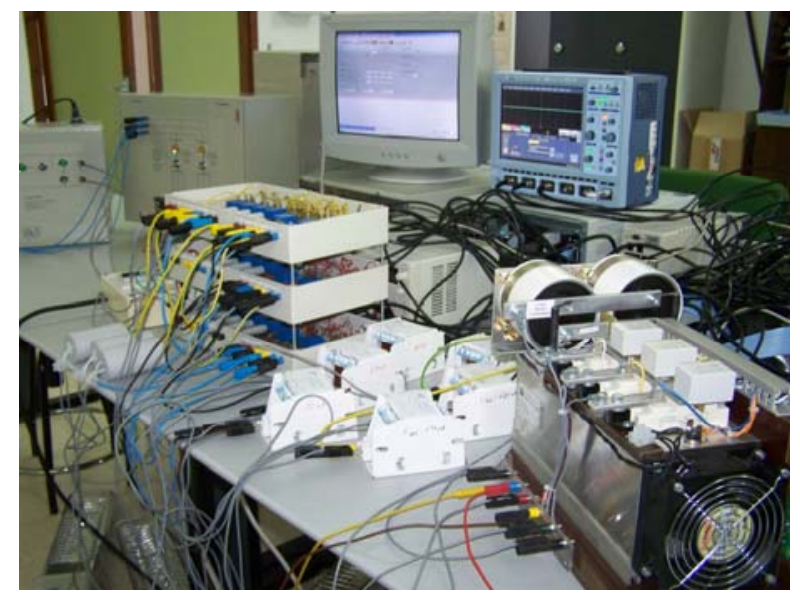

Fig 5. Experimental prototype

Fig. 6 shows the load current and voltage of the phase a, with the system without compensating. This waveform is obtained with an oscilloscope type Wavesurfer 424 from LECROY. The THD of the current measured with the power quality analyzer Fluke 43 is $21.5 \%$ and the voltage THD $11.2 \%$. The power factor measured is 0.96 . 


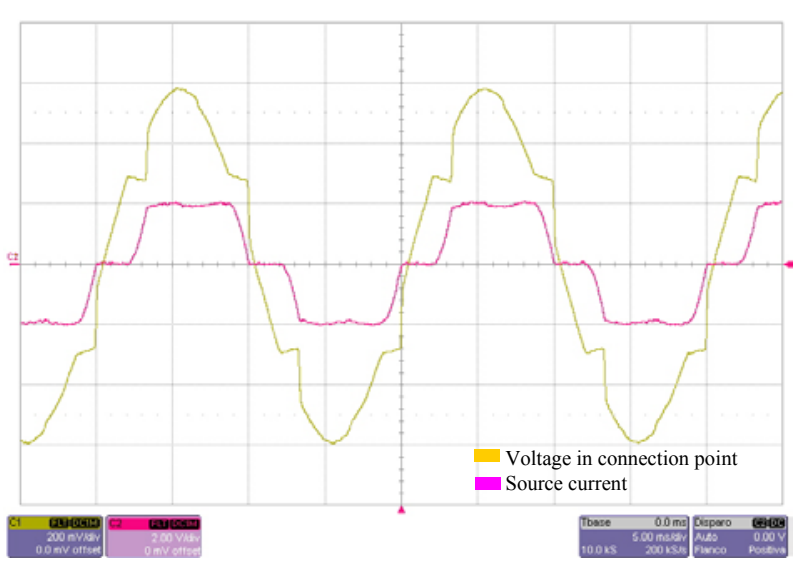

Fig 6. Voltage and current source, phase a. System without compensating

Fig. 7 shows the source current and voltage in the connection point when the shunt passive power filter is connected. This current and voltage have a THD of 5.1\% and $4.3 \%$ respectively. The passive power filter was only designed to compensate the source current harmonics; the reactive power was not taken into account. The power factor of the set load and passive filter is 0.86 .

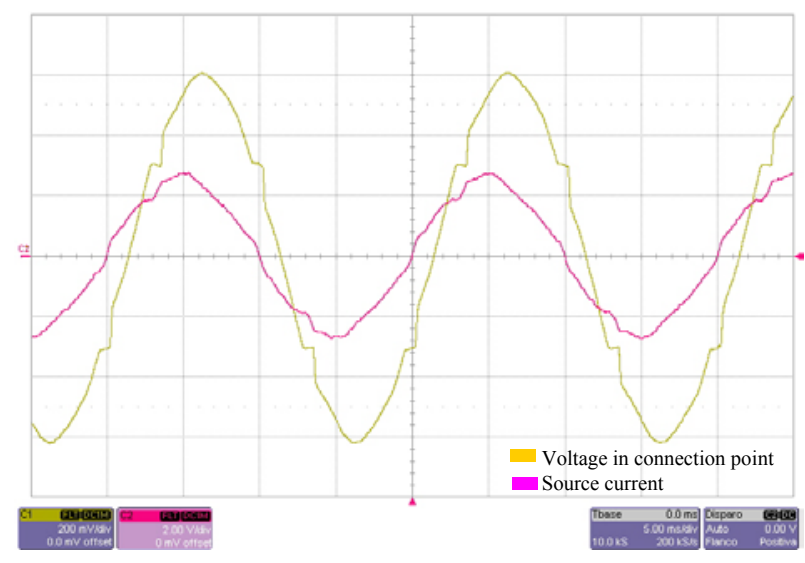

Fig 7. Voltage and current source, phase a, in the system with passive power filter

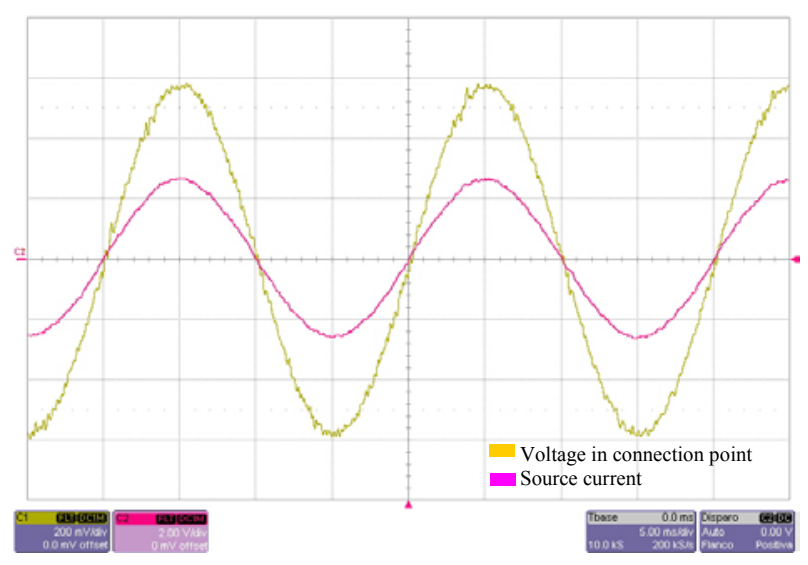

Fig 8. Voltage and current source, phase a, in the system with the hybrid power filter
For the phase $\mathrm{b}$ and $\mathrm{c}$, similar results of THD and power factor was measured.

When the series active filter is connected, the THD of the source current falls to $1.0 \%$. The waveform is shown in Fig. 8. Now, the power factor rises to 0.998 . This allows us to verify the proposed control improvement in the compensation characteristic of the passive filter and it practically achieves unity power factor. The THD of the voltage in the PCC is $1.35 \%$ and the waveform is shown in Fig. 8 with the phase current.

\section{Conclusions}

A new control algorithm for a series active filter has been proposed. The control strategy is based on the vectorial theory of electric power. The new control approach achieves the following targets:

- The compensation characteristics of the hybrid compensator do not depend on the system impedance.

- The hybrid power filter and load set are a behavior very similar to the one of a resistive element. This fact eliminates the risk of overload due to current harmonics of non linear loads close to the compensated system.

- This compensator can be applied to loads with random power variation as it is not affected by changes in the tuning frequency of the passive filter. Furthermore, the reactive power variation is compensated by the series active filter.

- Series and/or parallel resonances with the rest of the system are avoided because compensation equipment and load are behavior resistive.

Therefore, with the proposed control algorithm, the hybrid power filter improves the compensation features of the passive filter and the power factor of the load.

The system has been verified by means of an experimental prototype, applied to a non-linear threephase load. The experimental results are presented. This fact has allowed verification of the theoretical analysis developed.

\section{Acknowledgement}

This work is part of the projects "A new technique to reduce the harmonic distortion in electrical systems by means of equipment of active compensation", ref. DPI2004-03501, sponsored by the "Comisión Interministerial de Ciencia y Tecnología, CICYT, del 
Ministerio de Ciencia y Tecnología" of Spain, and "Design and implementation of a new equipment of active compensation with series connection for the improvement of the electrical waveform quality", ref. P06-TEP-02354, sponsored by the "Consejería de Innovación, Ciencia y Empresa de la Junta de Andalucía", of Andalucía, Spain.

\section{References}

[1] F. Z. Peng and D. J. Adams, "Harmonics sources and filtering approaches," in Proc. Industry Aplications Conference, October 1999, Vol, 1, pp. 448-455

[2] H. Akagi, "Active harmonic filters," Proceedings of the IEEE Volume 93, Issue 12, Dec. 2005 Page(s):2128 2141

[3] J.C. Das, "Passive Filters-Potentialities and Limitations", IEEE Trans. on Industry Applications, Vol. 40, no. 1, January 2004, pp. 232-241.

[4] F. Z. Peng, H. Akagi, A. Nabae, "A novel harmonic power filter," in Proc. IEEE/PESC, April, 1988, pp. 1151-1159.
[5] F. Z. Peng, H. Akagi, A. Nabae, "A new approach to harmonic compensation in power systems-a combined system of shunt passive and series active filters," IEEE Trans. Industry Applications. Vol, 26, no. 6, Nov/Dec 1990, pp. 983-990

[6] Z. Wang, Q. Wang, W. Yao and J. Liu, "A series active power filter adopting hybrid control approach," IEEE Trans. Power Electronics, vol. 16, no. 3, May 2001, pp. 301-310

[7] Y. S. Kim, J. S. Kim and S. H. Ko, "Three-Phase ThreeWire Series Active Power Filter, which Compensates for Harmonics and Reactive Power", IEE proc. Electr. Power Appl., Vol, 151, no. 3, May 2004, pp. 276-282.

[8] F. Z. Peng, J. S. Lai, "Generalized instantaneous reactive power theory for three phase power system", IEEE Trans. Instrum. Meas. 1996, 45, (1), pp. 293-297.

[9] Herrera, R. S.; Salmerón, P.; Kim, H.; "Instantaneous Reactive Power Theory Applied to Active Power Filter Compensation: Different Approaches, Assessment, and Experimental Results", IEEE Transactions on Industrial Electronics, Vol. 55, No. 1, Jan-2008, pp: 184 - 196

[10] P. Salmerón, R. S. Herrera, J. R. Vázquez, "Mapping matrices against vectorial frame in the instantaneous reactive power compensation", IET Electric Power Applications, Volume 1, № 5, September 2007, pp. $727-$ 736. 